pISSN 2073-1477

eISSN 2311-8733

ПОВЕДЕНИЕ ЭКОНОМИЧЕСКОЙ СИСТЕМЫ ТЕРРИТОРИИ: МЕТОДОЛОГИЯ АНАЛИЗА И КЛАССИФИКАЦИЯ СОСТОЯНИЙ УСТОЙЧИВОСТИ* Инесса Александровна ГУРБАН ${ }^{\mathrm{a}, \bullet}$, Мария Сергеевна ПЕЧЕРКИНА

а кандидат экономических наук, старший научный сотрудник, Институт экономики УрО РАН, Екатеринбург, Российская Федерация inessagurban@gmail.com

b аспирантка сектора теории и методологии экономической безопасности, Институт экономики УрО РАН, Екатеринбург, Российская Федерация maria09.06@mail.ru

• Ответственный автор

История статьи:

Получена 07.09.2015

Получена в доработанном

виде 24.09.2015

Одобрена 07.10.2015

Доступна онлайн 15.11.2017

УДК 33.332.1

JEL: E32, P51, R11

Ключевые слова: регион, устойчивое развитие, экономические кризисы, темпы роста, индекс промышленного производства

\section{Аннотация}

Тема. Статья посвящена разработке алгоритма, позволяющего проводить анализ вариантов поведения экономической системы отдельного региона с учетом изменений, происходящих в экономической ситуации в стране. Разработка системы диагностики устойчивости подчиненной экономической системы территории (экономики региона) относительно главной (экономики страны) представляет собой актуальную задачу в современных условиях.

Цели и задачи. Определение поведения экономической системы Уральского федерального округа (УрФО) относительно экономики Российской Федерации и экономической системы Свердловской области относительно экономики УрФО. Авторами были решены следующие задачи: выявлены основные причины кризисов в экономике России в период 1997-2015 гг.; разработан алгоритм диагностики устойчивости экономических систем; предложена классификация реакций подчиненной системы на процессы, происходящие в главной системе.

Методология. В данной работе с помощью метода анализа рядов динамики определена степень устойчивости подчиненной системы относительно главной и предложен классификатор, характеризующий реакции подчиненной системы на изменения экономической конъюнктуры, происходящие в главной системе.

Результаты. В статье приведена динамика темпов роста индекса промышленного производства в России, УрФО и Свердловской области, описаны результаты расчетов, характеризующие состояние промышленности в период 1997-2015 гг. с акцентом на кризисные годы.

Выводы. Установлено, что состояние экономической системы УрФО относительно экономики страны в кризисные периоды 1998 и 2009 гг. характеризовалось как уязвимое. В 2014 г. реакция экономики УрФО на кризис в стране была менее болезненной: экономическая система округа характеризовалась как слабоустойчивая, находилась в состоянии стагнации. Экономика Свердловской области относительно экономики Уральского федерального округа в 1998 и 2009 гг. оказалась еще менее устойчивой: система показала регресс. Однако в 2014 г. реакция экономики Свердловской области на кризис была совершенно иной: она проявила себя как устойчивая, показав рост на фоне падения экономики УрФО.

(C) Издательский дом ФИНАНСЫ и КРЕДИТ, 2015

Для цитирования: Гурбан И.А., Печеркина М.С. Поведение экономической системы территории: методология анализа и классификация состояний устойчивости // Региональная экономика: теория и практика. - 2017. - Т. 15, № 11. - С. 1992 - 2014.

https://doi.org/10.24891/re.15.11.1992

\footnotetext{
* Статья подготовлена при финансовой поддержке Российского гуманитарного научного фонда, грант № 14-02-00101а «Оценка социально-экономических последствий от вступления России в ВТО».

Статья публикуется по материалам журнала «Национальные интересы: приоритеты и безопасность», 2016. Т. 12. Вып. 1.
} 


\section{Введение}

Социально-экономическое развитие страны невозможно без устойчивого развития регионов. Развитие отдельного региона необходимо рассматривать не только в связи с общими законами функционирования национальной экономики, но и с учетом специфических особенностей самих регионов (условий производства, ресурсного потенциала, менталитета населения и др.).

Термин «устойчивое развитие» был сформулирован Международной комиссией по окружающей среде и развитию (Комиссия Брунтланд) в 1987 г. Под устойчивым развитием подразумевается такой тип социально-экономического развития, при котором удовлетворяются потребности живущего в настоящее время населения и одновременно не ставится под угрозу способность будущих поколений удовлетворять свои потребности ${ }^{1}$.

Устойчивое развитие предполагает три аспекта ${ }^{2}$ :

1) экономический - в экономически устойчивой системе должны производиться товары и услуги на постоянной основе, чтобы сохранять управляемые уровни власти и внешнего долга, а также избегать крайних диспропорций, которые наносят вред сельскому хозяйству и промышленному производству;

2) социальный - в социально устойчивой системе должны достигаться «распределительное» равенство, адекватное предоставление социальных услуг, включая здравоохранение и

\footnotetext{
${ }^{1}$ Report of the World Commission on Environment and Development: Our Common Future. 1987. URL: http://un-documents.net/our-common-future.pdf

${ }^{2}$ Harris J.M. Basic Principles of Sustainable Development. URL: https://notendur.hi.is/bdavids/UAU 101/Readings/Harris_2000_Sustainable_development.p df
}

образование, гендерное равенство. Социально устойчивая система должна обеспечивать политическую ответственность и участие;

3) экологический - в экологически устойчивой системе должна поддерживаться стабильная ресурсная база без чрезмерной эксплуатации возобновляемых ресурсов с использованием невозобновляемых ресурсов только в той мере, в которой инвестиции сделаны в их адекватные заменители. Экологически устойчивая система подразумевает сохранение биологического разнообразия, устойчивости атмосферы и других функций экосистемы, которые обычно не классифицируются как экономические ресурсы.

Итак, устойчивое развитие социальноэкономической системы понимается как развитие трех ее составляющих экономической, социальной и экологической. Оно подразумевает реализацию двух ключевых положений: во-первых, на текущий момент времени - обеспечение выполнения целей функционирования системы и противостояние негативным воздействиям различного характера и, во-вторых, в будущем - сохранение возможности удовлетворения этих целей на качественно более высоком уровне.

В работах зарубежных специалистов ${ }^{3}$ [1-4] рассматриваются различные методы анализа устойчивого развития, где чаще всего можно выделить два этапа оценки устойчивости: количественную оценку реального развития социальноэкономической системы и собственно оценку устойчивости развития системы. Количественная оценка фактического

${ }^{3}$ Caratti P., Ferraguto L. Analysing Regional Sustainability through a systemic approach: the Lombardy case study. Social Science Research Network Electronic Paper Collection. URL: http://ssrn.com/abstr act $=1140637$ 
состояния

социально-экономической

системы или ее подсистем производится на

основе одного или нескольких

обобщающих показателей или путем

объединения нескольких частных

индикаторов в один сводный индекс. По составляющим устойчивого развития для оценки сложившегося уровня развития системы в зарубежных работах в основном используются следующие индикаторы:

- по экономической составляющей валовой внутренний продукт на душу населения, прямые иностранные инвестиции на душу населения и уровень безработицы;

- по социальной составляющей - средняя полезная площадь на душу населения, количество преступлений на 100000 чел., расходы на социальное обеспечение и образование в процентах ВВП;

- по экологической составляющей площадь лесных угодий по отношению к территории страны, объемы загрязняющих веществ, выбрасываемые в атмосферу на душу населения, объем загрязненных и недостаточно очищенных сточных вод, сбрасываемых в поверхностные воды.

В работе [5] сформирована система показателей для количественной оценки развития страны, которая может быть использована для определения устойчивости ее развития. Система оценки состоит из 45 элементов: 11 индикаторов, описывающих экономическое развитие, 30 -социальное и 4 индикаторов оценки развития окружающей среды. По сути, оценки устойчивости социальноэкономических систем, приведенные в данной работе, сводятся к оценкам сложившегося состояния данных систем.

Устойчивое развитие отдельного региона желательно рассматривать с учетом циклического характера развития экономики страны, когда за периодом подъема неизбежно следует спад. Согласно инновационно-циклической теории Шумпетера-Кондратьева, экономическое развитие носит волновой характер [6], при этом повышательной фазе экономического цикла предшествует спад производства, переходящий к кризису [7-9]. В период подъема экономики начинается оживление производства, формируется устойчивый спрос, растет уровень жизни населения. При этом экономический рост может вызывать и определенные негативные последствия, выражающиеся в превышении совокупного предложения над потребительским спросом, которому сопутствует расширение масштабов кредитования. Это, в свою очередь, неизбежно провоцирует кризисные явления в экономике 4 . В такой период устойчивое развитие заключается в регулировании производства и в осуществлении грамотной денежно-кредитной политики, направленной на создание платежеспособного спроса у населения. В период экономического спада устойчивость развития региона заключается в способности реагировать на снижение экономической активности таким образом, чтобы ключевые для региона отрасли производства, население и бизнес реагировали меньшим темпом.

Происходящие в экономике кризисы можно рассматривать как препятствие к достижению устойчивого развития регионов ${ }^{5}$. Как известно, возникновение кризиса может быть связано не только с циклами деловой активности, но и с действием различного рода факторов. Например, в последние годы на фоне

${ }^{4}$ Напалкова А.В. Опережающие индикаторы начала подготовки условий экономического кризиса // Вестник Череповецкого государственного университета. 2012. № 4. Т. 1. С. 57-61.

${ }^{5}$ Baiardi D., Percoco M. Economic structure, reaction to the crisis and entrepreneurs expectations in a mature regional economy: The case of Lombardy. 2012. The Consequences of the International Crisis for European SMEs: Vulnerability and Resilience, pp. 222-239. 
углубления международной интеграции различные страны оказываются тесно связанными через систему межбанковских, информационных и торговых отношений таким образом, что происходящий в одной стране «шок» быстро передается другой возникает так называемый «эффект заражения», когда кризис из одной страны перетекает в другую. Исследованием этого вопроса занимались многие зарубежные ученые [10-13]. Также в зарубежной литературе множество исследований по с в я ено изучени ю в и дов и классификации кризисов, среди которых обычно выделяют финансовые, валютные, долговые, банковские кризисы, а также «внезапную остановку» (sudden stop crises) и самосбывающиеся кризисы (self-fulfilling crises $)^{6}[14]$.

Экономическое развитие России в постсоветский период также характеризовалось циклической динамикой - экономическими подъемами и спадами. Экономический кризис 1997-1998 гг. был спровоцирован событиями, произошедшими в странах Восточной Азии во второй половине 1990-х гг. [15]. Экономики азиатских стран в высокой степени были зависимы от экспорта продукции и импорта капитала на международных рынках, имели большие объемы иностранных заимствований и искусственно заданные обменные валютные курсы [16]. Неэффективность экономик азиатских стран и несамостоятельный характер их развития вызвали избыточное перепроизводство, что при неразвитости внутренних рынков повлекло падение экспортных цен на выпускаемую продукцию. Последствием азиатского кризиса 1997-1998 гг. стало падение мировых цен на нефть.

\footnotetext{
${ }^{6}$ Claessens $S$, Kose M.A. Financial Crises: Explanations, Types, and Implications. IMF Working Paper, 2013, pp. 1-40; Kaminsky G. Varieties of Currency Crises. NBER Working Paper, 2003, no. 10193, pp. 1-31.
}

К концу 1990-х гг. экономика России, находясь в высокой зависимости от цен на нефть, проявляла признаки финансовой неустойчивости, что в итоге повлекло неспособность государства платить по своим краткосрочным обязательствам, и 17 августа 1998 г. Правительство РФ было вынуждено объявить дефолт. Таким образом, причинами кризиса в России стала совокупность внешних и внутренних факторов: падение мировых цен на нефть и другие сырьевые товары; чрезмерно большой внешний долг; жесткая монетарная политика страны в середине 1990-х гг., направленная на сдерживание инфляции за счет удержания завышенного курса рубля и отказа от эмиссии денег [17]; пирамида государственных краткосрочных облигаций (ГКО).

Финансово-экономический кризис 1998 г. привел к падению курса рубля, параличу и подрыву доверия к банковской системе, резкому падению уровня доходов и качества жизни населения. В качестве положительных последствий кризиса можно назвать разрушение пирамиды ГКО, возможность начать реструктуризацию внешнего долга и выработку собственной экономической стратегии, нацеленной на внутренние приоритеты страны [18].

В 2008-2009 гг. экономический кризис в России был вызван последствиями глобального мирового финансовоэкономического кризиса, спровоцированного крахом финансового рынка в США, связанным, в частности, с политикой низких процентных ставок и проблемами на рынке ипотечного кредитования. В основе кризиса в России специалисты выделяют группы макроэкономических, микроэкономических и институциональных предпосылок [19-22]: глобализационные процессы в развитии мировой экономики, изменение направления движения капитала, рост капитализации компаний, чрезмерный объем внешних заимствований, искусственное 
стимулирование экономического роста, ориентацию национальной экономики и экспорта на топливные и сырьевые источники, неудовлетворительное состояние банковского сектора.

В период между кризисами в России наблюдались рост экономики и благосостояния населения, улучшение социальной политики государства. Стабильный продолжительный экономический рост, профицитный бюджет, увеличение объема золотовалютных резервов способствовали снижению внимания к причинам и последствиям финансового кризиса 1998 г. . За прошедшие 15 лет Россия интегрировалась в мировую экономическую и политическую системы, что способствовало углублению зависимости страны от конъюнктуры мирового рынка энергоносителей и состояния мировой экономики. В результате введения и реализации антикризисных мер удалось несколько смягчить негативные последствия экономического кризиса 2008-2009 гг., однако структурные и системные причины кризиса, разумеется, ликвидированы не были.

На фоне замедления темпов роста мировой экономики Россия с 2010 по 2012 г. демонстрировала устойчивый рост (в 20102011 гг. - 4\% в год, в 2012 г. - 3,5\%) благодаря относительно устойчивому потреблению ${ }^{8}$. При этом темпы экономического роста в данный период составляли лишь половину от средних темпов роста экономики России за 10 лет, предшествовавших кризису 2008-2009 гг. Уже 2013 г. закончился существенным снижением темпов экономического роста

\footnotetext{
${ }^{7}$ Цветкова Е.А. Специфика финансовых причин системного экономического кризиса 2008 года // Актуальные проблемы гуманитарных и естественных наук. 2009. № 4. С. 102-105.

${ }^{8}$ Улатов С., Титов С., Матыциин М., Емельянова О. Доклад об экономике России № 29. Восстановление и перспективы дальнейшего развития экономики. URL: http://worldbank.org/conte nt/dam/Worldbank/document/eca/RER29-RUS.pdf
}

(до $1,4 \%)^{9}$ [22]. Особенно сильно сократились темпы роста в промышленности: так в 2013 г. фактически произошла остановка промышленного роста (в годы экономического подъема 1999-2008 гг. среднегодовой темп прироста промышленного производства составлял $6,1 \%)^{10}$. И, наконец, в 2014 г. к экономическим причинам стагнации добавились внешнеполитические: события в Украине, санкции США и европейских стран в ответ на присоединение Крыма к РФ, последующий резкий спад мировых цен на энергоресурсы, который спровоцировал новый виток экономического кризиса ${ }^{11}$.

\section{Методология анализа}

Экономика региона (субъекта РФ) является составной частью экономической системы страны и зависит от ее состояния. Степень зависимости бывает разной, что связано с уровнем развития региона, специализацией его экономики, социальнодемографическими характеристиками, климатическими особенностями, географическим положением и др. Именно поэтому региональная экономическая система каждой территории может реагировать на кризисы по-разному. Преодоление последствий кризиса на региональном уровне становится возможным благодаря анализу факторов, которые характеризуют поведение регионов относительно поведения национальной экономической системы.

\footnotetext{
${ }^{9}$ Кравченко Л.И. Социально-экономические итоги 2013 г. URL: http://rusrand.ru/actuals/sotsialnoekonomicheskie-itogi-2013-goda

${ }^{10}$ Баранов А.О. Замедление экономического роста в России и перспективы его преодоления. URL: http://ecotrends.ru/subscribe/1764-2013-11-2811-12-47

${ }^{11}$ Улатов С., Титов С., Матыциин М., Емельянова О., Поллнер Дю. Доклад об экономике России № 33. Начало новой экономической эры? URL: http://worldbank.org/content/dam/Worldbank/doc ument/eca/russia/rer33-rus.pdf
} 
Авторами был разработан методологический подход к оценке устойчивости подчиненной экономической системы относительно главной, основанный на анализе рядов динамики индикаторов, характеризующих экономические процессы. На первом этапе рассчитываются коэффициенты роста для главной системы $G-D_{g}^{(t, t+1)}$ и подчиненной системы $S-D_{s}^{(t, t+1)}$. Далее определяются $R_{g s}^{(t, t+1)}-$ произведения коэффициентов роста главной и подчиненной систем. На следующем шаге $R_{g s}^{(t, t+1)}$ соотносится с $D_{g}^{(t, t+1)}$ и делается вывод о поведении главной и подчиненной систем на текущий момент времени $t+1$ относительно предыдущего t. Алгоритм расчетов, осуществляемый на первом этапе, согласно которому теоретически существуют лишь три варианта изменения коэффициента роста главной системы за исследуемый период - снижение, рост либо нулевое изменение - приведен на puc. 1. На схеме приведены все математически возможные варианты, но в дальнейшем, при практическом применении данного подхода, были исключены ситуации нулевого изменения коэффициента роста, поскольку на практике этот случай может произойти с минимальной вероятностью.

На втором этапе рассчитываются и сравниваются темпы роста главной системы $G-r_{g}^{(t, t+1)}$ и подчиненной системы $S-r_{s}^{(t, t+1)}$, алгоритм расчетов которых представлен на рис. 2. Далее предлагается следующая классификация реакций подчиненной системы $S$ на процессы, происходящие в главной системе $G$, на основе расчета конкретного индикатора, выбранного для анализа:

1) если и главная, и подчиненная системы демонстрируют рост, при этом темп роста подчиненной системы больше темпа роста главной системы, то состояние подчиненной системы характеризуется как устойчивое;
2) если и главная, и подчиненная системы демонстрируют рост, при этом темп роста подчиненной системы меньше темпа роста главной системы, то подчиненная система переживает стагнацию, a еe состояние характеризуется как слабо устойчивое;

3) если главная система демонстрирует рост, а подчиненная система - спад, при этом, разумеется, темп роста подчиненной системы меньше темпа роста главной системы, то подчиненная система переживает падение, a eе состояние характеризуется как депрессивное;

4) если главная система падает, а подчиненная система растет, при этом темп роста подчиненной системы больше темпа роста главной системы, то подчиненная система переживает подъем, a eе состояние характеризуется как стабильное;

5) если и главная, и подчиненная системы демонстрируют спад, при этом темп роста подчиненной системы больше темпа роста главной системы, то подчиненная система переживает рецессию, а ее состояние характеризуется как уязвимое;

6) если и главная, и подчиненная системы падают, при этом темп роста подчиненной системы меньше темпа роста главной системы, то подчиненная система переживает регресс, a eе состояние характеризуется как неустойчивое.

Данный подход предназначен для диагностики реакции экономических систем региона на изменения конъюнктуры в экономике страны либо для оценки реакции экономической системы страны на изменения мировой экономической конъюнктуры. Инструментами в данном алгоритме могут выступать ключевые 
макроэкономические индикаторы, такие как валовой внутренний продукт (ВВП), валовой региональный продукт (ВРП), показатели промышленного производства, торгового оборота, объема инвестиций и т.п.

Предложенный подход был апробирован на анализе индекса промышленного производства (ИПП), поскольку зачастую именно состояние промышленного производства характеризует «самочувствие» экономики территории, а во время кризисных периодов ИПП наиболее оперативно отражает происходящие процессы. Кроме того, ИПП относительный показатель, характеризующий изменение масштабов производства в сравниваемых периодах ${ }^{12}$ Индекс промышленного производства определяется как отношение реального (физического) объема производства в стоимостном выражении к объему промышленного производства в предыдущем или другом базисном году ${ }^{13}$ и рассматривается как часть валового регионального продукта (ВРП). Последний также характеризует процесс производства товаров и услуг, представляет собой валовую добавленную стоимость товаров и услуг, созданную резидентами региона, и рассчитывается как разница между выпуском и промежуточным потреблением. ИПП характеризует изменение ВРП за счет базовых отраслей: добычи полезных ископаемых, обрабатывающих производств, производства и распределения электроэнергии, газа и воды. Таким образом, ИПП - один из главных индикаторов состояния экономики страны, отражающий экономическую

\footnotetext{
12 Индекс производства. Основные понятия. Федеральная служба государственной статистики. URL: http://gks.ru/free_doc/new_site/metod/prom/met ip.htm

${ }^{13}$ Об утверждении официальной статистической методологии исчисления индекса промышленного производства: приказ Федеральной службы государственной статистики от 08.05.2014 № 301. URL: http://garant.ru/products/ipo/prime/doc/70555960/ \#ixzz3fqo7pneC
}

динамику региона, и, в отличие от ВРП, рассчитывается каждый месяц.

\section{Результаты анализа и классификация состояний устойчивости}

Проанализируем реакцию экономических систем Уральского федерального округа и Свердловской области на кризисные процессы, наблюдавшиеся в экономике России за прошедшие 17 лет, основываясь на анализе динамики их ИПП согласно предложенному алгоритму (см. puc. 1 и 2). Значения ИПП для Российской Федерации (РФ) и Уральского федерального округа (УрФО) за 1997-2014 гг. представлены в табл. 1 .

Финансово-экономический кризис 1998 г. проявился в падении индекса промышленного производства в России на $4,8 \%$, а в УрФО - на 2,4\%. При этом негативные проявления были замечены в экономике Уральского федерального округа уже в 1997 г., а при росте ИПП в России на $1 \%$ состояние экономики округа, согласно заданной классификации, характеризовалось как депрессивное. От кризиса 1998 г. больше всего пострадало обрабатывающее производство, индекс которого в России снизился на $6,2 \%$, а в УрФО - на $8,2 \%$ (для сравнения добывающее производство и производство электроэнергии, газа и воды упали в среднем на 1,8\%). После кризиса конца 1990-х гг. динамика промышленности довольно быстро вышла на траекторию роста: в 1999 г. ИПП в России вырос на $8,9 \%$, в УрФО - на 3,1\%.

Как следует из данных табл. 1, в 1999 г. по сравнению с кризисным годом состояние экономики УрФО улучшилось: в 1998 г. система характеризовалась как уязвимая, наблюдалась рецессия, в 1999 г. - как слабоустойчивая (стагнация). При этом динамика индекса промышленного производства различается в регионах с разной хозяйственной специализацией. 
В 1999 г. наибольший рост показали регионы, специализирующиеся на черной и цветной металлургии - Свердловская $(10,7 \%)$ и Челябинская $(10,7 \%)$ области, что связано с ростом объемов производства вследствие положительной внешнеэкономической конъюнктуры и улучшения внутренних экономических условий для металлургических предприятий. Наибольшее снижение ИПП $(-7,9 \%)$ было отмечено в слаборазвитой в промышленном отношении Курганской области. Несмотря на благоприятную внешнеэкономическую динамику, регионы, ориентированные на ТЭК - ХантыМансийский автономный округ (ХМАО) и Ямало-Ненецкий автономный округ (ЯНАО) - в 1999 г. были далеки от устойчивого роста: снижение ИПП составило $0,1 \%$ и $0,2 \%$ соответственно.

В период кризиса 2008-2009 гг. падение промышленного производства в УрФО было более глубоким по сравнению с кризисом 1998 г., но вновь менее серьезным, чем в среднем по России. Хотя в 2009 г. падение ИПП в России составило $10,7 \%$, в УрФО - 9,1\% (на 6,7\% больше, чем в 1998 г.), состояние экономики округа определялось в 2008 г. как депрессивное (падение). В 2009 г. по составляющим ИПП сложилась аналогичная ситуация: больше всего пострадало обрабатывающее производство. Так, в России значение индекса снизилось на $15,2 \%$, а в УрФО - на $18,5 \%$ (для сравнения: добывающее производство и производство электроэнергии, газа и воды упали в среднем на 3,3\%). В период экономического кризиса наибольший промышленный спад в УрФО наблюдался в Курганской области (в обрабатывающем производстве падение составило 25,6\%). Менее всего последствия кризиса повлияли на нефтедобывающий ХантыМансийский автономный округ.
C 2010 г. началось постепенное восстановление промышленности в стране: по сравнению с 2009 г. ИПП в России вырос на 7,3\%, в УрФО - на 4,3\%. При сравнении темпов роста ИПП России и УрФО заметно, что промышленное производство в целом по стране восстанавливалось заметно быстрее. Проанализировав годовую динамику ИПП (см. табл. 1), можно сделать вывод, что индекс после резкого роста в 2010 г. (на фоне низкой базы предыдущего года) постепенно снижал свое значение.

В период 2010-2014 гг. экономическая ситуация стабилизировалась, в это время состояние экономики УрФО характеризуется как слабоустойчивое, а экономическая система пребывает в фазе стагнации. Отставание темпов роста ИПП в УрФО от среднероссийского показателя связано с медленным выходом из кризиса Тюменской области с автономными округами. Отрицательные темпы роста за период 2010-2014 гг. сохранились в добывающей отрасли, в частности в добыче топливноэнергетических полезных ископаемых ${ }^{14}$.

Обратимся к анализу поведения экономической системы Свердловской области в кризисные периоды относительно экономической системы Уральского федерального округа: ИПП УрФО и Свердловской области за период $1997-$ 2014 гг. представлены в табл. 2.

Свердловская область является крупным промышленным регионом Уральского федерального округа с мощным обрабатывающим комплексом, который также оказался подвержен влиянию финансово-экономических кризисов. Так, в 1998 г. объемы промышленного производства Свердловской области

\footnotetext{
${ }^{14}$ Индексы производства по отдельным видам экономической деятельности в Тюменской области. URL: http:/tumstat.gks.ru/wps/wcm/connect/rosstat ts/ tumstat/resources/96acbd004d1576849363bbc5b34c73c 1/Индексы+производства.htm
} 
снизились на 5,6\%, в среднем по УрФО - на $2,4 \%$. ИПП по области снизился в среднем больше, чем по округу, и состояние экономики Свердловской области определялось как неустойчивое, система демонстрировала регресс. Уже с 1999 г. показатели промышленности области вновь вышли на траекторию устойчивого роста, который прекратился под влиянием кризиса 2008-2009 гг. Кризис повлек снижение спроса на продукцию металлургических производств, и состояние экономики области вновь получило статус неустойчивого, продемонстрировав регресс.

Из составляющих промышленности Свердловской области в период кризиса 2008-2009 гг. наибольшему падению подверглась обрабатывающая отрасль. Падение ИПП в 2009 г. составило 20,7\%, и наблюдалось по всем обрабатывающим отраслям: больше всего пострадало производство транспортных средств и оборудования (ИПП снизился на 47,5\%), неметаллической минеральной продукции (на $37,4 \%$ ), производство резиновых и пластмассовых изделий (на 32,9\%). Металлургическое производство играет ключевую роль в экономике Свердловской области, его доля в обрабатывающих отраслях в 2008 г. составляла $60,5 \%$, снижаясь под влиянием кризиса до 57,8\% в 2010 г. и до 54,3\% в 2013 г. В структуре обрабатывающей промышленности области значительный удельный вес приходится на производство машин, транспортных средств и оборудования, доля которых выросла за 2007-2013 гг. с 8,9 до 12,3\%.

Обратимся к анализу текущей ситуации в промышленности Уральского федерального округа. В период с января 2014 г. по апрель 2015 г. динамика промышленного производства была неоднозначной (табл. 3). Практически весь 2014 г. темп роста промышленности был отрицательным, причем ИПП Свердловской области падал сильнее, чем ИПП
Уральского федерального округа. Согласно предложенной классификации, состояние экономической системы УрФО определялось как неустойчивое (регресс). Как уже отмечалось, экономика России в 2014 г. подверглась влиянию двух серьезных шоков: во-первых, введению экономических санкций, а во-вторых, более чем двукратному падению цен на нефть, что не могло не отразиться на состоянии промышленного производства. Из данных, приведенных в табл. 3, следует, что наибольшее падение ИПП в Свердловской области наблюдалось в октябре и ноябре 2014 г. (-6,4\% и $-10,7 \%$ соответственно), и что примечательно, декабрь 2014 г. закончился ростом ИПП на 25,5\%. Этот факт можно отчасти объяснить низкой базой 2013 г. (99,2\%). Больше всего в декабре 2014 г. по сравнению с декабрем предыдущего года выросло производство машин и оборудования (на 108\%); это связано с тем, что производство идет по длинному инвестиционному циклу, что увеличивает колебания от месяца к месяцу, поэтому в целом за год прирост составил всего $9,1 \%{ }^{15}$.

В 2014 г. Правительством РФ была поставлена задача по импортозамещению, что, вероятно, оказало некоторое влияние на рост объемов производства пищевых продуктов в Свердловской области, который за январь-декабрь 2014 г. составил $22,1 \%$ по сравнению с аналогичным периодом 2013 г. В результате производство сыров в годовом исчислении выросло на $31 \%$, маргариновой продукции - на 14,2, кондитерских изделий - на $18,3 \%$. Существенно увеличилось производство деревянных строительных конструкций (на 33\%), механического оборудования (на 23,4), препаратов для лечения сердечнососудистых заболеваний (на 14,4\%).

\footnotetext{
15 Официальный сайт Федеральной службы государственной статистики. URL: http://gks.ru/regio n/docl1165/IssWWW.exe/Stg/2014-12/i120003r.htm
} 
В период с января по апрель 2015 г. в Свердловской области отмечалось падение промышленного производства, при этом в январе-феврале данный процесс проходил на фоне продолжавшегося роста ИПП в УрФО, и состояние экономики области определялось как депрессивное (падение), то в последующие месяцы ИПП УрФО также начал падать. В разрезе составляющих ИПП добыча полезных ископаемых снизилась за I кв. 2015 г. в среднем на $13 \%$, обрабатывающее производство выросло в феврале и апреле 2015 г. лишь на 2\%, производство и распределение электроэнергии, газа и воды упало в рассмотренный период на 2,7\%. В 2015 г. среди основных факторов, ограничивающих рост производства, предпринимателями были названы:

- в сфере добычи полезных ископаемых: недостаточный спрос на внутреннем рынке, высокий уровень налогообложения, недостаток финансовых средств и изношенность и отсутствие оборудования;

- в сфере обрабатывающего производства: недостаточный спрос на внутреннем рынке, высокий уровень налогообложения, неопределенность экономической ситуации и недостаток финансовых средств;

- в сфере производства и распределения электроэнергии, газа и воды: изношенность и отсутствие оборудования, высокий уровень налогообложения ${ }^{16}$.

Для оценки уровня деловой активности предприятий Росстатом рассчитывается индекс предпринимательской уверенности, позволяющий определить стабильность финансового положения предприятия в условиях рынка и его позицию в контактах с деловыми партнерами (табл. 4-6). При рассмотрении динамики данного индекса за период 2007-2015 гг. в разрезе основных видов промышленной деятельности можно

\footnotetext{
${ }^{16}$ Официальный сайт Федеральной службы государственной статистики. URL: http://gks.ru
} сй наиболе успеш стабильной за весь период являлась добыча полезных ископаемых (значения индекса в данном секторе выше, чем в других за весь анализируемый период). В период перед кризисом - с января 2007 г. по октябрь 2008 г. индекс имел положительные значения, при этом тенденция его снижения наметилась еще с августа 2008 г. Кризис 2008-2009 гг. выразился в резком снижении индекса: больше всего его значения упали в секторе обрабатывающих производств (до 20\%) в январе 2009 г. В посткризисный период отрицательные значения индекса сохранились, что говорит о сохранении негативного влияния кризисных явлений. События второго полугодия 2014 г. привели к еще большему снижению индекса в секторе добычи полезных ископаемых (до 7\%) и в обрабатывающем производстве (до $10 \%$ ). Противоположная ситуация сложилась в секторе производства и распределения электроэнергии, газа и воды, что связано с сезонностью данного вида деятельности.

\section{Выводы}

Состояние промышленного производства в регионах имеет огромное влияние на социально-экономическое развитие страны: увеличение его объемов ведет к росту доходов субъектов экономической деятельности, участвующих в процессе производства товаров и услуг. Это, в свою очередь, приводит к росту налогооблагаемой базы и увеличению возможностей по перераспределению части доходов в пользу тех, кто непосредственно в процессе промышленного производства не участвует. Подобным образом промышленность взаимосвязана с другими секторами экономики и оказывает наиболее сильное воздействие на социальноэкономическое развитие территории по сравнению с другими видами деятельности. 
Устойчивое экономическое развитие территорий подразумевает преодоление кризисных явлений путем быстрого восстановления экономики в посткризисный период. Чем устойчивее экономика региона относительно экономической системы страны, тем выше его (региона) потенциал по преодолению и сопротивлению неблагоприятным факторам. Предложенный подход анализа рядов динамики индикаторов позволяет проводить экспрессоценку устойчивости подчиненной экономической системы (региона) относительно главной (страны), охарактеризовать согласно представленной классификации состояние протекающего в подчиненной системе процесса, а также оценивать изменения в поведении экономической системы с использованием любых ключевых индикаторов. Преимуществами данного подхода являются простота в использовании, универсальность, детальное и исчерпывающее определение реакций системы, в том числе в кризисные периоды. Простота применения предложенного алгоритма дает возможность проводить широкомасштабный анализ по всем регионам России.

Кризисы оказывают существенное влияние на состояние промышленного производства в стране, особенно на сектор обрабатывающих производств, вызывая замедление темпов роста или даже сильное падение. Проведенный анализ показал, что на сегодняшний день промышленность страны продолжает пребывать в кризисном состоянии.

Текущее состояние национальной экономики можно охарактеризовать как структурный кризис (кризис сырьевой модели развития). Рассматривая влияние кризисов на промышленное производство в России, нельзя не учитывать провоцирующие кризисные явления факторы.

Так, кризис 1998 г. произошел на фоне тяжелой экономической ситуации в стране после смены экономических режимов и был усилен падением мировых цен на нефть; кризис 2008-2009 гг. был глобальным, циклическим, системным, что проявилось в еще более глубоком падении экономики России; кризис 2014 г. был усугублен политическими факторами, которые привели опять же к падению цен на нефть и резкой девальвации рубля.

Данные процессы не могли не повлиять на устойчивое развитие регионов страны. Согласно введенной авторами классификации, состояние экономической системы УрФО относительно экономики страны в кризисные периоды 1998 и 2009 гг. характеризовалось как уязвимое, то есть экономика округа находилась в состоянии рецессии. В 2014 г. реакция экономики УрФО на кризис в стране была менее болезненной: экономическая система округа характеризовалась как слабоустойчивая, находилась в состоянии стагнации. Экономика Свердловской области относительно экономики Уральского федерального округа в 1998 и 2009 гг. оказалась еще менее устойчивой: система показала регресс. В то же время в 2014 г. реакция экономики Свердловской области на кризис была совершенно иной: она проявила себя как устойчивая, показав рост на фоне падения экономики УрФО. 


\section{Таблица 1}

Индексы промышленного производства в РФ и УрФО в период 1997-2014 гг.

Table 1

Industrial production indices in the Russian Federation and Ural Federal District in 1997-2014

\begin{tabular}{lccccccc}
\hline \multicolumn{1}{c}{ Показатель } & $\mathbf{1 9 9 7}$ & $\mathbf{1 9 9 8}$ & $\mathbf{1 9 9 9}$ & $\mathbf{2 0 0 0}$ & $\mathbf{2 0 0 7}$ & $\mathbf{2 0 0 8}$ \\
\hline$D_{\mathrm{P \Phi}}$ & 1,01 & 0,952 & 1,089 & 1,087 & 1,068 & 1,006 \\
\hline$D_{\text {УрФО }}$ & 0,987 & 0,976 & 1,031 & 1,069 & 1,032 & 0,98 \\
\hline$R_{\mathrm{P} \Phi}^{\mathrm{Уp}}$ & 0,997 & 0,929 & 1,123 & 1,162 & 1,102 & 0,986 \\
\hline$r_{\mathrm{P \Phi}}, \%$ & 1 & $-4,8$ & 8,9 & 8,7 & 6,8 & 0,6 \\
\hline$r_{\text {УРфо }} \%$ & $-1,3$ & $-2,4$ & 3,1 & 6,9 & 3,2 & -2 \\
\hline
\end{tabular}

Состояние экономической системы Уральского федерального округа относительно экономики Российской Федерации

\begin{tabular}{lccccccc}
\hline $\begin{array}{l}\text { Характеристика } \\
\text { процесса }\end{array}$ & П & Р & СТ & СТ & СТ & П \\
\hline Состояние системы & Д & У & СУ & СУ & СУ & Д \\
\hline
\end{tabular}

Продолжение табл. 1

\begin{tabular}{lccccccc}
\hline \multicolumn{1}{c}{ Показатель } & $\mathbf{2 0 0 9}$ & $\mathbf{2 0 1 0}$ & $\mathbf{2 0 1 1}$ & $\mathbf{2 0 1 2}$ & $\mathbf{2 0 1 3}$ & $\mathbf{2 0 1 4}$ \\
\hline$D_{\mathrm{P \Phi}}$ & 0,893 & 1,073 & 1,05 & 1,034 & 1,004 & 1,017 \\
\hline$D_{\text {УрФО }}$ & 0,909 & 1,043 & 1,019 & 1,016 & 1,011 & 1,001 \\
\hline$R_{\mathrm{P} \Phi}^{\mathrm{Уp}}$ & 0,812 & 1,119 & 1,07 & 1,051 & 1,015 & 1,018 \\
\hline$r_{\mathrm{P} \Phi}, \%$ & $-10,7$ & 7,3 & 5 & 3,4 & 0,4 & 1,7 \\
\hline$r_{\mathrm{Ур} \Phi О} \%$ & $-9,1$ & $-4,3$ & 1,9 & 1,6 & 1,1 & 0,1 \\
\hline
\end{tabular}

Состояние экономической системы Уральского федерального округа относительно экономики

\begin{tabular}{|c|c|c|c|c|c|c|}
\hline \multicolumn{7}{|c|}{ Российской Федерации } \\
\hline $\begin{array}{l}\text { Характеристика } \\
\text { процесса }\end{array}$ & $\mathrm{P}$ & $\mathrm{CT}$ & $\mathrm{CT}$ & CT & $\mathrm{PC}$ & $\mathrm{CT}$ \\
\hline Состояние системы & $\mathrm{Y}$ & CY & CY & $\mathrm{CY}$ & $\mathrm{y}$ & $\mathrm{CY}$ \\
\hline
\end{tabular}

Примечание. $D_{\text {РФ }}$ - коэффициент роста ИПП Российской Федерации; $D_{\text {УрФО }}-$ коэффициент роста ИПП Уральского федерального округа; $R_{\mathrm{P} Ф}^{\mathrm{Уp}}-$ произведение коэффициентов ИПП РФ и УрФО; $r_{\text {РФ }}-$ темп роста ИПП Российской Федерации; $r_{\text {урФо }}$ - темп роста ИПП Уральского федерального округа.

Характеристика процесса: П - падение; Р - рецессия; СТ - стагнация; РС - рост. Состояние системы: Д - депрессивное; У - уязвимое; СУ - слабо устойчивое.

Источник: расчеты авторов, данные Росстата

Source: Authoring, based on the Rosstat data 


\section{Таблица 2}

Индексы промышленного производства в УрФО и Свердловской области в период 1997-2014 гг.

Table 2

Industrial production indices in the Ural Federal District and Sverdlovsk oblast in 1997-2014

\begin{tabular}{lccccccc}
\multicolumn{1}{c}{ Показатель } & $\mathbf{1 9 9 7}$ & $\mathbf{1 9 9 8}$ & $\mathbf{1 9 9 9}$ & $\mathbf{2 0 0 0}$ & $\mathbf{2 0 0 7}$ & $\mathbf{2 0 0 8}$ \\
\hline$D_{\mathrm{yp} \Phi О}$ & 0,987 & 0,976 & 1,031 & 1,069 & 1,032 & 0,98 \\
\hline$D_{\mathrm{CO}}$ & 0,91 & 0,944 & 1,107 & 1,167 & 1,073 & 0,954 \\
\hline$R_{\mathrm{yp} \Phi \mathrm{CO}}^{\mathrm{CO}}$ & 0,898 & 0,921 & 1,141 & 1,248 & 1,107 & 0,935 \\
\hline$r_{\mathrm{y} \Phi \Phi О}, \%$ & $-1,3$ & $-2,4$ & 3,1 & 6,9 & 3,2 & -2 \\
\hline$r_{\mathrm{CO}}, \%$ & -9 & $-5,6$ & 10,7 & 16,7 & 7,3 & $-4,6$ \\
\hline
\end{tabular}

1. Состояние экономической системы Свердловской области относительно экономики Уральского федерального округа

\begin{tabular}{|c|c|c|c|c|c|c|}
\hline $\begin{array}{l}\text { Характеристика } \\
\text { процесса }\end{array}$ & РГ & РГ & $\mathrm{PC}$ & $\mathrm{PC}$ & $\mathrm{PC}$ & $\mathrm{P} \Gamma$ \\
\hline Состояние системы & HУ & HУ & $\mathrm{YC}$ & $\mathrm{YC}$ & $\mathrm{YC}$ & HУ \\
\hline \multicolumn{7}{|l|}{ Продолжение табл. 2} \\
\hline Показатель & 2009 & 2010 & 2011 & 2012 & 2013 & 2014 \\
\hline$D_{\mathrm{yp} \Phi О}$ & 0,909 & 1,043 & 1,019 & 1,016 & 1,011 & 1,001 \\
\hline$D_{\mathrm{CO}}$ & 0,811 & 1,173 & 1,062 & 1,096 & 1,027 & 1,008 \\
\hline$R_{\mathrm{yp} \Phi \mathrm{CO}}^{\mathrm{CO}}$ & 0,737 & 1,223 & 1,082 & 1,114 & 1,038 & 1,009 \\
\hline$r_{\mathrm{yp} \Phi О}, \%$ & $-9,1$ & 4,3 & 1,9 & 1,6 & 1,1 & 0,1 \\
\hline$r_{\mathrm{CO}}, \%$ & $-18,9$ & 17,3 & 6,2 & 9,6 & 2,7 & 0,8 \\
\hline
\end{tabular}

2. Состояние экономической системы Свердловской области относительно экономики Уральского

\begin{tabular}{llccccc}
\multicolumn{9}{c}{ федерального округа } \\
\hline $\begin{array}{l}\text { Характеристика } \\
\text { процесса }\end{array}$ & PГ & PГ & PC & PC & PC & PC \\
\hline Состояние системы & НУ & НУ & УC & УC & УC & УC \\
\hline
\end{tabular}

Примечание. $D_{\text {УрФо }}$ - коэффициент роста ИПП Уральского федерального округа; $D_{\mathrm{CO}}-$ коэффициент роста ИПП Свердловской области; $R_{\mathrm{y} Ф О}^{\mathrm{CO}}$ - произведение коэффициентов ИПП УрФО и Свердловской области; $r_{\text {УрФО }}$ - темп роста ИПП Уральского федерального округа; $r_{\mathrm{CO}}-$ темп роста ИПП Свердловской области. Характеристика процесса: РГ - регресс; РС - рост. Состояние системы: НУ - неустойчивое; УС устойчивое.

Источник: расчеты авторов, данные Росстата

Source: Authoring, based on the Rosstat data 


\section{Таблица 3}

Индексы промышленного производства УрФО и Свердловской области в период январь 2014 г. - апрель 2015 г.

Table 3

Industrial production indices in the Ural Federal District and Sverdlovsk oblast within January, 2014 to April, 2015

\begin{tabular}{|c|c|c|c|c|c|c|c|c|}
\hline \multirow{2}{*}{ Показатель } & \multicolumn{8}{|c|}{ Месяцы 2014 г. } \\
\hline & 01 & 02 & 03 & 04 & 05 & 06 & 07 & 08 \\
\hline$D_{\mathrm{yp} \Phi О}$ & 0,989 & 0,941 & 0,967 & 0,978 & 1,018 & 1,001 & 0,959 & 1,018 \\
\hline$D_{\mathrm{CO}}$ & 0,967 & 0,808 & 0,882 & 0,947 & 1,094 & 0,996 & 0,894 & 1,156 \\
\hline$R_{\mathrm{yp} \Phi \mathrm{CO}}^{\mathrm{CO}}$ & 0,956 & 0,76 & 0,853 & 0,926 & 1,114 & 0,997 & 0,857 & 1,177 \\
\hline$r_{\mathrm{Уp} \Phi О}, \%$ & $-1,1$ & $-5,9$ & $-3,3$ & $-2,2$ & 1,8 & 0,1 & $-4,1$ & 1,8 \\
\hline$r_{\mathrm{CO}}, \%$ & $-3,3$ & $-19,2$ & $-11,8$ & $-5,3$ & 9,4 & $-0,4$ & $-10,6$ & 15,6 \\
\hline
\end{tabular}

Состояние экономической системы Свердловской области относительно экономики Уральского

\begin{tabular}{|c|c|c|c|c|c|c|c|c|}
\hline \multicolumn{9}{|c|}{ федерального округа } \\
\hline $\begin{array}{l}\text { Характеристика } \\
\text { процесса }\end{array}$ & $\mathrm{P}$ & $\mathrm{P}$ & $\mathrm{P}$ & $\mathrm{P}$ & $\mathrm{PC}$ & $\Pi$ & $\mathrm{P}$ & $\mathrm{PC}$ \\
\hline $\begin{array}{l}\text { Состояние } \\
\text { системы }\end{array}$ & $\mathrm{y}$ & $\mathrm{y}$ & $\mathrm{y}$ & $\mathrm{y}$ & $\mathrm{yC}$ & Д & $\mathrm{y}$ & $\mathrm{C}$ \\
\hline
\end{tabular}

Продолжение табл. 3

\begin{tabular}{|c|c|c|c|c|c|c|c|c|}
\hline \multirow{2}{*}{ Показатель } & \multicolumn{4}{|c|}{ Месяцы 2014 г. } & \multicolumn{4}{|c|}{ Месяцы 2015 г. } \\
\hline & 09 & 10 & 11 & 12 & 01 & 02 & 03 & 04 \\
\hline$D_{\mathrm{yp} \Phi О}$ & 1,02 & 0,977 & 0,976 & 1,07 & 1,007 & 1,002 & 0,999 & 0,985 \\
\hline$D_{\mathrm{CO}}$ & 1,102 & 0,936 & 0,893 & 1,255 & 0,963 & 0,99 & 0,943 & 0,958 \\
\hline$R_{\mathrm{yp} \Phi O}^{\mathrm{CO}}$ & 1,124 & 0,914 & 0,872 & 1,343 & 0,97 & 0,992 & 0,942 & 0,944 \\
\hline$r_{\text {УрФО }}, \%$ & 2 & $-2,3$ & $-2,4$ & 7 & 0,7 & 0,2 & $-0,1$ & $-1,5$ \\
\hline$r_{\mathrm{CO}}, \%$ & 10,2 & $-6,4$ & $-10,7$ & 25,5 & $-3,7$ & -1 & $-5,7$ & $-4,2$ \\
\hline
\end{tabular}

Состояние экономической системы Свердловской области относительно экономики Уральского

\begin{tabular}{|c|c|c|c|c|c|c|c|c|}
\hline \multicolumn{9}{|c|}{ федерального округа } \\
\hline $\begin{array}{l}\text { Характеристика } \\
\text { процесса }\end{array}$ & $\mathrm{PC}$ & $\mathrm{P}$ & $\mathrm{P}$ & PC & $\Pi$ & $\Pi$ & $\mathrm{P}$ & $\mathrm{P}$ \\
\hline $\begin{array}{l}\text { Состояние } \\
\text { системы }\end{array}$ & $\mathrm{YC}$ & HУ & HУ & $\mathrm{y}$ & Д & Д & $\mathrm{y}$ & $\mathrm{y}$ \\
\hline
\end{tabular}

Примечание. $D_{\text {урФо }}$ - коэффициент роста ИПП Уральского федерального округа; $D_{\mathrm{CO}}-$ коэффициент роста ИПП Свердловской области; $R_{\text {урФо }}^{\mathrm{CO}}$ - произведение коэффициентов ИПП УрФО и Свердловской области; $r_{\text {УрФО }}$ - темп роста ИПП Уральского федерального округа; $r_{\mathrm{CO}}$ - темп роста ИПП Свердловской области. Характеристика процесса: $\mathrm{P}$ - рецессия; РС - рост; П - падение. Состояние системы: НУ - неустойчивое; УС - устойчивое; У - уязвимое; Д - депрессивное.

Источник: расчеты авторов, данные Росстата

Source: Authoring, based on the Rosstat data 


\section{Таблица 4}

Индекс предпринимательской уверенности в секторе добычи полезных ископаемых в Свердловской области в 2007-2015 гг. (по месяцам), \%

Table 4

Business confidence index in the mining sector of the Sverdlovsk oblast in 2007-2015 (by month), percent

\begin{tabular}{|c|c|c|c|c|c|c|c|c|c|c|c|c|}
\hline \multirow{2}{*}{ Год } & \multicolumn{12}{|c|}{ Месяц } \\
\hline & 01 & 02 & 03 & 04 & 05 & 06 & 07 & 08 & 09 & 10 & 11 & 12 \\
\hline 2007 & - & 4 & 5 & 5 & 6 & 8 & 7 & 6 & 3 & 1 & 1 & 1 \\
\hline 2008 & 4 & 6 & 6 & 8 & 8 & 10 & 9 & 10 & 6 & 3 & -8 & -16 \\
\hline 2009 & -14 & -12 & -12 & -9 & -7 & -5 & -4 & -7 & -7 & -9 & -12 & -13 \\
\hline 2010 & -8 & -2 & -1 & - & 3 & 2 & 5 & 3 & 2 & - & -2 & -3 \\
\hline 2011 & -1 & 1 & 3 & 4 & 5 & 6 & 6 & 4 & 4 & - & -3 & -3 \\
\hline 2012 & -1 & 3 & 5 & 7 & 7 & 9 & 8 & 5 & 4 & - & -2 & -5 \\
\hline 2013 & -3 & 1 & 3 & 4 & 4 & 4 & 4 & 4 & 1 & -2 & -3 & -5 \\
\hline 2014 & -5 & -3 & -1 & - & 1 & - & - & -4 & -1 & -4 & -5 & -7 \\
\hline 2015 & -7 & -5 & -5 & -5 & -3 & -2 & -2 & - & - & - & - & - \\
\hline
\end{tabular}

Источник: данные Росстата

Source: Rosstat data

\section{Таблица 5}

Индекс предпринимательской уверенности в секторе обрабатывающего производства в Свердловской области в 2007-2015 гг. (по месяцам), \%

Table 5

Business confidence index in the manufacturing sector of the Sverdlovsk oblast in 2007-2015 (by month), percent

\begin{tabular}{|c|c|c|c|c|c|c|c|c|c|c|c|c|}
\hline \multirow{2}{*}{ Год } & \multicolumn{12}{|c|}{ Месяц } \\
\hline & 01 & 02 & 03 & 04 & 05 & 06 & 07 & 08 & 09 & 10 & 11 & 12 \\
\hline 2007 & 1 & 4 & 4 & 4 & 4 & 6 & 7 & 5 & 5 & 2 & 1 & -1 \\
\hline 2008 & 2 & 4 & 5 & 4 & 4 & 5 & 5 & 4 & 2 & -1 & -11 & -20 \\
\hline 2009 & -20 & -17 & -16 & -16 & -16 & -14 & -14 & -14 & -13 & -13 & -15 & -15 \\
\hline 2010 & -11 & -8 & -6 & -6 & -5 & -3 & -2 & -2 & -2 & -3 & -4 & -6 \\
\hline 2011 & -4 & -1 & - & -1 & -1 & - & - & -1 & -1 & -2 & -4 & -6 \\
\hline 2012 & -3 & -2 & - & 1 & - & 1 & 2 & 1 & 1 & -1 & -3 & -5 \\
\hline 2013 & -2 & - & - & -1 & - & -1 & -1 & -1 & -3 & -5 & -6 & -8 \\
\hline 2014 & -6 & -4 & -2 & -3 & -2 & -3 & -3 & -4 & -6 & -6 & -8 & -10 \\
\hline 2015 & -9 & -6 & -6 & -5 & -6 & -6 & -6 & - & - & - & - & - \\
\hline
\end{tabular}

Источник: данные Росстата

Source: Rosstat data 


\section{Таблица 6}

Индекс предпринимательской уверенности в секторе распределения электроэнергии, газа, воды в Свердловской области в 2007-2015 гг. (по месяцам), \%

Table 6

Business confidence index in the electricity, gas and water distribution sector of the Sverdlovsk oblast in 2007-2015 (by month), percent

\begin{tabular}{|c|c|c|c|c|c|c|c|c|c|c|c|c|}
\hline \multirow{2}{*}{ Год } & \multicolumn{12}{|c|}{ Месяц } \\
\hline & 01 & 02 & 03 & 04 & 05 & 06 & 07 & 08 & 09 & 10 & 11 & 12 \\
\hline 2007 & -3 & -8 & -12 & -13 & -14 & -2 & - & 3 & 3 & 3 & 3 & 3 \\
\hline 2008 & 2 & -1 & -3 & -3 & -4 & -2 & -2 & 1 & 3 & 6 & 5 & 1 \\
\hline 2009 & -2 & -6 & -5 & -8 & -6 & -8 & -5 & -2 & 2 & 3 & 2 & - \\
\hline 2010 & -4 & -6 & -6 & -9 & -8 & -7 & -2 & 3 & 6 & 7 & 8 & 6 \\
\hline 2011 & -2 & -7 & -10 & -12 & -12 & -7 & -1 & 3 & 7 & 8 & 8 & 6 \\
\hline 2012 & -1 & -6 & -11 & -14 & -14 & -10 & -2 & 3 & 7 & 9 & 8 & 6 \\
\hline 2013 & -4 & -13 & -16 & -20 & -20 & -6 & -2 & 2 & 8 & 9 & 9 & 6 \\
\hline 2014 & 2 & -5 & -9 & -12 & -13 & -8 & -4 & 1 & 4 & 7 & 6 & 4 \\
\hline 2015 & -2 & -8 & -11 & -14 & -13 & -10 & -5 & - & - & - & - & - \\
\hline
\end{tabular}

Источник: данные Росстата

Source: Rosstat data 


\section{Рисунок 1}

\section{Алгоритм расчета (этап 1)}

Figure 1

\section{Calculation algorithm (Step 1)}

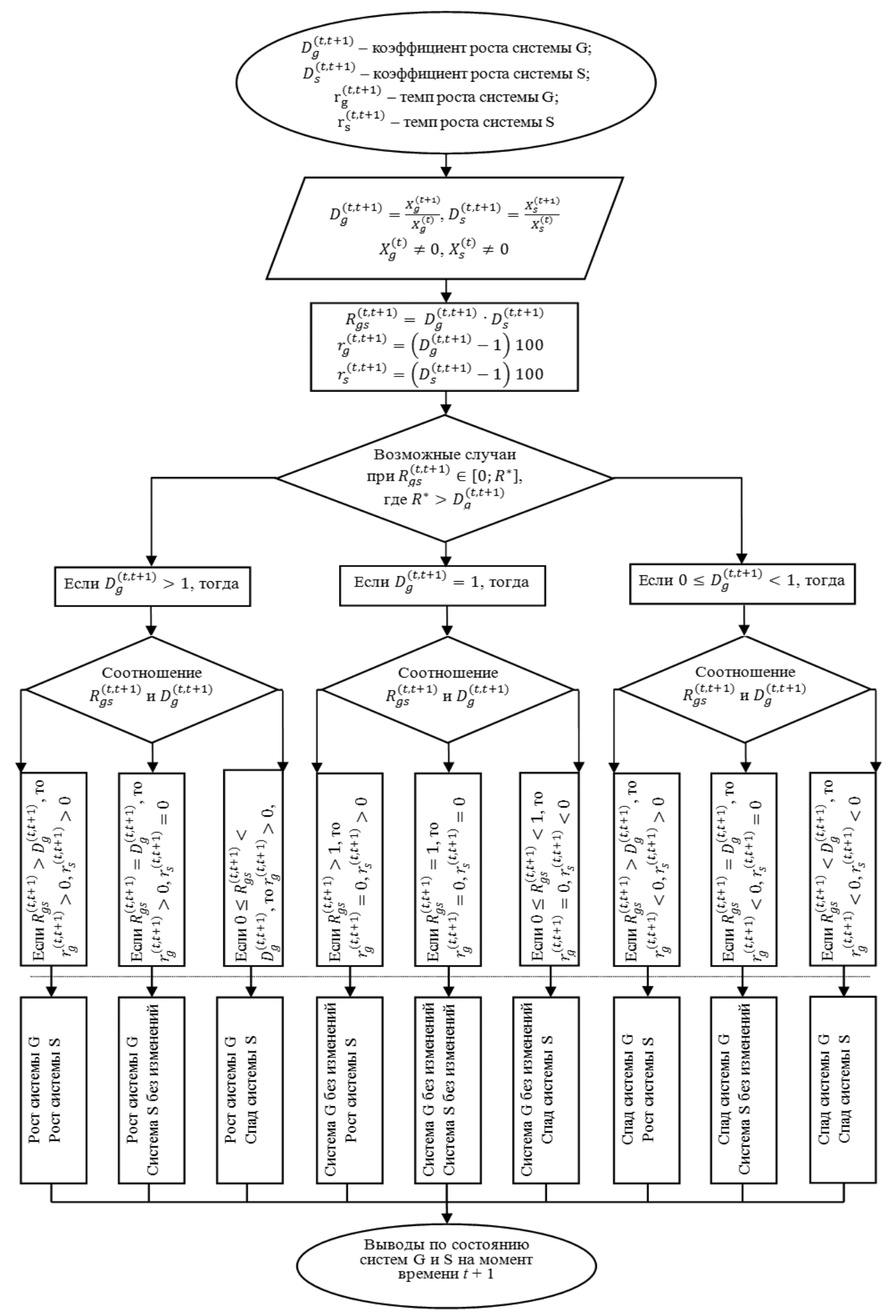

Источник: составлено авторами

Source: Authoring 


\section{Рисунок 2}

\section{Алгоритм расчета (этап 2)}

Figure 2

Calculation algorithm (Step 2)

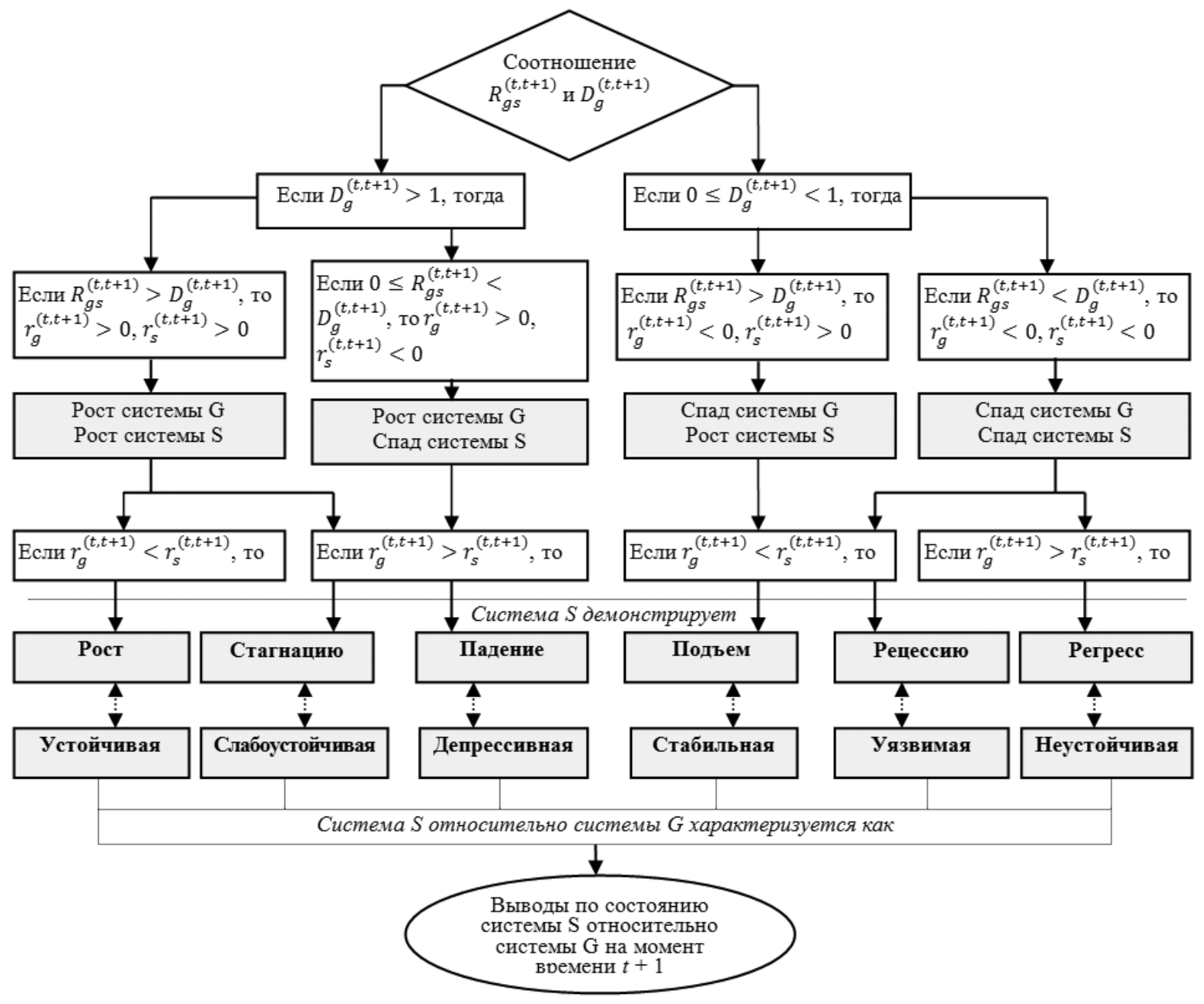

Источник: составлено авторами

Source: Authoring

\section{Список литературы}

1. Floridi M., Pagni S., Falorni S.L. An Exercise in Composite Indicators Construction:

Assessing the Sustainability of Italian Regions. Ecological Economics, 2011, vol. 70, iss. 8, pp. 1440-1447.

2. Bell D., Morse S. Sustainability Indicators: Measuring the Immeasurable? London, Earthscan, 228 p.

3. Rotmans J. Tools for Integrated Sustainability Assessment: A Two-Track Approach. Integrated Assessment - Bridging Sciences \& Policy, 2006, vol. 6, no. 4, pp. 35-57.

4. Parris T.M., Kates R.W. Characterizing and Measuring Sustainable Development. Annual Review of Environment and Resources, 2003, no. 28, pp. 559-586. 
5. Ginevicius R., Hogeforster M., Gedvilait D. The Formation of the System of Indicators of Development of the Country's Regions. Proc. 8th Int. Sci. Conf. Business and Management 2014, May 15-16, 2014. Lithuania, Vilnius, Vilnius Gediminas Technical University, pp. 503-510.

6. Акаев A.A. Большие циклы конъюнктуры и инновационно-циклическая теория экономического развития Шумпетера-Кондратьева // Экономическая наука современной России. 2013. № 2. С. 7-28.

7. Глазьев С.Ю. Современная теория длинных волн в развитии экономики // Экономическая наука современной России. 2012. № 2. С. 27-42.

8. Коротаев А.В., Гришин Л.Е. Н.Д. Кондратьев и Кондратьевские волны в мировой техноинновационной активности // Экономическая наука современной России. 2013. № 2. C. $128-136$.

9. Дементьев В.E. Инвестиционные ориентиры датировки длинных волн в развитии экономики // Экономическая наука современной России. 2013. № 4. С. 23-39.

10. Eichengreen B., Rose A., Wyplocz C. Contagious Currency Crises: First Tests. Scandinavian Journal of Economics, 1996, no. 98, pp. 463-484.

11. Freixas X., Parigi B. Contagion and Efficiency in Gross and Net Interbank Payment Systems. Journal of Financial Intermediation, 1998, vol. 7, iss. 1, pp. 3-31.

12. Masson P.R. Contagion: Monsoonal Effects, Spillovers, and Jumps Between Multiple Equilibria. IMF Working Papers, 1998, no. 98/142, p. 4.

13. Azis I.J., Mitra S., Baluga A. Global Shock and Regional Spillovers. Peace Economics, Peace Science and Public Policy, 2013, vol. 13, iss. 2, pp. 183-211.

14. Panizza U., Sturzenegger F., Zettelmeyer J. The Economics and Law of Sovereign Debt and Default. Journal of Economic Literature, 2009, vol. 47, no. 3, pp. 65-98.

15. Шавшуков В.М. Кризисы глобальных финансов (1997-2013 гг.) // Вестник СанктПетербургского университета. Сер. 5. Экономика. 2013. Вып. 4. С. 87-109.

16. Цветков B.A. Циклы и кризисы: теоретико-методологический аспект. М.: Нестористория, 2013. $504 \mathrm{c.}$

17. Сенчагов В.К., Митяков С.Н. Сравнительный анализ влияния финансовоэкономических кризисов 1998 г. и 2008-2009 гг. на индикаторы экономической безопасности России // Вестник Финансового университета. 2013. № 6. С. 71-88.

18. Митяев Д.А. Задачи антикризисного управления // Экономические стратегии. 1999. T. 1. № 1. C. 77-88.

19. Кудрин А.Л. Мировой финансовый кризис и его влияние на Россию // Вопросы экономики. 2009. № 1. С. 9-27.

20. Фролов Д. Теория кризисов после кризиса: технология versus институты // Вопросы экономики. 2011. № 7. С. 17-33. 
21. Лавров С.Ю. Макроэкономическая основа цикличности экономического развития в современных условиях // Журнал экономической теории. 2014. № 1. С. 122-134.

22. Сухарев О.С. Экономическая теория кризисов: ретроспектива и современность // Журнал экономической теории. 2014. № 3. С. 30-46.

\section{Информация о конфликте интересов}

Мы, авторы данной статьи, со всей ответственностью заявляем о частичном и полном отсутствии фактического или потенциального конфликта интересов с какой бы то ни было третьей стороной, который может возникнуть вследствие публикации данной статьи. Настоящее заявление относится к проведению научной работы, сбору и обработке данных, написанию и подготовке статьи, принятию решения о публикации рукописи. 
pISSN 2073-1477

eISSN 2311-8733

Theory of Regional Economy

\title{
BEHAVIOR OF THE LOCAL ECONOMIC SYSTEM: AN ANALYSIS METHODOLOGY AND CLASSIFICATION OF SUSTAINABILITY CONDITIONS
}

\section{Inessa A. GURBAN ${ }^{a, \bullet}$, Mariya S. PECHERKINA ${ }^{\mathrm{b}}$}

a Institute of Economics, Ural Branch of Russian Academy of Sciences, Yekaterinburg, Russian Federation inessagurban@gmail.com

${ }^{\mathrm{b}}$ Institute of Economics, Ural Branch of Russian Academy of Sciences, Yekaterinburg, Russian Federation maria09.06@mail.ru

- Corresponding author

\section{Article history:}

Received 7 September 2015

Received in revised form 24 September 2015

Accepted 7 October 2015

Available online

15 November 2017

JEL classification: E32, P51, R11

Keywords: region, sustainable development, economic crises, growth rates, industrial production index

\begin{abstract}
Importance The research develops an algorithm for analyzing the economic system behavior in a certain region, considering changes in the national economy.

Objectives The research determines the economic system behavior of the Ural Federal District in relation to the Russian economy, and economic system of the Sverdlovsk oblast in relation to the economy of the Ural Federal District.

Methods Using the dynamics time series analysis, we assessed the sustainability of a subordinate system against a superior one and proposed the classifier describing how the subordinate system responded to changes in the main system.

Results The article shows growth trends in the industrial production index of Russia, Ural Federal District and the Sverdlovsk oblast, provides the assessment of the industry within the 1997-2015 period, focusing on the years of crisis.

Conclusions and Relevance The economic system of the Ural Federal District has been proved to be vulnerable against the national economy. In 2014, the economy of the Ural Federal District was less susceptible to the national crisis. In 1998 and 2009, the economy of the Sverdlovsk oblast was less stable against the economy of the Ural Federal District. In 2014, the economy of the Sverdlovsk oblast responded in a different way, being sustainable and growing.
\end{abstract}

(C) Publishing house FINANCE and CREDIT, 2015

Please cite this article as: Gurban I.A., Pecherkina M.S. Behavior of the Local Economic System: An Analysis Methodology and Classification of Sustainability Conditions. Regional Economics: Theory and Practice, 2017, vol. 15, iss. 11, pp. 1992-2014. https://doi.org/10.24891/re.15.11.1992

\section{Acknowledgments}

The article was supported by the Russian Foundation for Humanities, grant No. 14-02-00101a Assessing the Socio-economic Impact of Russia's Accession to the WTO.

The article is adapted from the National Interests: Priorities and Security journal, 2016, vol. 12, iss. 1.

\section{References}

1. Floridi M., Pagni S., Falorni S.L., Luzzati T. An Exercise in Composite Indicators

Construction: Assessing the Sustainability of Italian Regions. Ecological Economics, 2011, vol. 70 , iss. 8 , pp. $1440-1447$.

2. Bell D., Morse S. Sustainability Indicators: Measuring the Immeasurable? London, Earthscan, 2008, 228 p. 
3. Rotmans J. Tools for Integrated Sustainability Assessment: A Two-Track Approach. Integrated Assessment - Bridging Sciences \& Policy, 2006, vol. 6, no. 4, pp. 35-57.

4. Parris T.M., Kates R.W. Characterizing and Measuring Sustainable Development. Annual Review of Environment and Resources, 2003, no. 28, pp. 559-586.

5. Ginevicius R., Hogeforster M., Gedvilait D. The Formation of the System of Indicators of Development of the Country's Regions. Proc. 8th Int. Sci. Conf. Business and Management 2014, May 15-16. Lithuania, Vilnius, Vilnius Gediminas Technical University, 2014, pp. 503-510.

6. Akaev A.A. [Big cycles of economic conditions and the Schumpeter-Kondratieff theory of innovation and cyclical economic growth]. Ekonomicheskaya nauka sovremennoi Rossii = Economic Science in Modern Russia, 2013, no. 2, pp. 7-28. (In Russ.)

7. Glaz'ev S.Yu. [The modern theory of long waves in economic development].

Ekonomicheskaya nauka sovremennoi Rossii = Economic Science in Modern Russia, 2012, no. 2, pp. 27-42. (In Russ.)

8. Korotaev A.V., Grishin L.E. N.D. [N.D. Kondratieff and the Kondratieff waves in global technological and innovative activities]. Ekonomicheskaya nauka sovremennoi Rossii $=$ Economic Science in Modern Russia, 2013, no. 2, pp. 128-136. (In Russ.)

9. Dement'ev V.E. [Investment milestones for fixing dates of long waves as part of economic development]. Ekonomicheskaya nauka sovremennoi Rossii = Economic Science in Modern Russia, 2013, no. 4, pp. 23-39. (In Russ.)

10. Eichengreen B., Rose A., Wyplocz C. Contagious Currency Crises: First Tests. Scandinavian Journal of Economics, 1996, no. 98, pp. 463-484.

11. Freixas X., Parigi B. Contagion and Efficiency in Gross and Net Interbank Payment Systems. Journal of Financial Intermediation, 1998, vol. 7, iss. 1, pp. 3-31.

12. Masson P.R. Contagion: Monsoonal Effects, Spillovers, and Jumps Between Multiple Equilibria. IMF Working Papers, 1998, no. 98/142, p. 4.

13. Azis I.J., Mitra S., Baluga A. Global Shock and Regional Spillovers. Peace Economics, Peace Science and Public Policy, 2013, vol. 13, iss. 2, pp. 183-211.

14. Panizza U., Sturzenegger F., Zettelmeyer J. The Economics and Law of Sovereign Debt and Default. Journal of Economic Literature, 2009, vol. 47, no. 3, pp. 65-98.

15. Shavshukov V.M. [Global finance crises (1997-2013)]. Vestnik Sankt-Peterburgskogo universiteta. Seriya 5. Ekonomika = Bulletin of St. Petersburg University. Series 5. Economics, 2013, no. 4, pp. 87-109. (In Russ.)

16. Tsvetkov V.A. Tsikly i krizisy: teoretiko-metodologicheskii aspekt [Cycles and crises: theoretical and methodological considerations]. Moscow, Nestor-istoriya Publ., 2013, 504 p.

17. Senchagov V.K., Mityakov S.N. [A comparative analysis of the impact of the 1998 and 2008-2009 financial and economic crises on Russia's economic security indicators]. Vestnik Finansovogo universiteta $=$ Bulletin of the Financial University, 2013, no. 6, pp. 71-88. (In Russ.) 
18. Mityaev D.A. [Crisis management objectives]. Ekonomicheskie strategii = Economic Strategies, 1999, vol. 1, no. 1, pp. 77-88. (In Russ.)

19. Kudrin A.L. [Global financial crisis and its impact on Russia]. Voprosy Ekonomiki, 2009, no. 1, pp. 9-27. (In Russ.)

20. Frolov D. [Theory of crises after crisis: technologies versus institutions]. Voprosy Ekonomiki, 2011, no. 7, pp. 17-33. (In Russ.)

21. Lavrov S.Yu. [Macroeconomic basis for the cyclical nature of economic development under modern circumstances]. Zhurnal ekonomicheskoi teorii = Journal of Economic Theory, 2014, no. 1, pp. 122-134. (In Russ.)

22. Sukharev O.S. [The economic theory of crises: a retrospective view and contemporary times]. Zhurnal ekonomicheskoi teorii = Russian Journal of Economic Theory, 2014, no. 3, pp. 30-46. (In Russ.)

\section{Conflict-of-interest notification}

We, the authors of this article, bindingly and explicitly declare of the partial and total lack of actual or potential conflict of interest with any other third party whatsoever, which may arise as a result of the publication of this article. This statement relates to the study, data collection and interpretation, writing and preparation of the article, and the decision to submit the manuscript for publication. 